\title{
PERANCANGAN SISTEM INFORMASI AKADEMIK PADA SEKOLAH MENENGAH KEJURUAN NEGERI (SMKN) I LINTAU BUO MENGGUNAKAN PHP MYSQL
}

\author{
Eko Amri Jaya ${ }^{1)}$,Veni Wedyawati ${ }^{2)}$ M. Ridwan ${ }^{3)}$ \\ Sistem Informasi, Sekolah Tinggi Teknologi Industri Padang \\ Email : ekoamrijaya@sttind.ac.id
}

\begin{abstract}
ABSTRAK: Penerapan sebuah situs akademik di sebuah sekolah menjadi salah satu bentuk sikap dalam mempertunjukkan atau memperlihatkan informasi kepada masyrakat. Dengan adanya situs akademik yang efektif pada sebuah sekolah dapat memberikan nilai tambah lebih baik untuk sekolah tersebut maupun untuk siswa dan walisiswa serta juga masyarakat yang ingin mengetahui informasi apasaja dari sekolah itu. Sekolah Menengah Kejuruan Negeri 1 Lintau Buo (SMK N 1 Lintau Buo) adalah salah satu Sekolah Menengah Kejuruan berstandar Nasional (SMK SSN) di Kabupaten Tanah Datar yang perlu berinteraksi dan bersosialisasi kepada masyarakat luas dengan memberikan informasi yang lengkap dan jelas mengenai sekolah tersebut. Sebelumnya sekolah ini belum pernah mempunyai Sistem Informasi Akademik sebagai media promosi, penerimaan siswa baru dan pemberian informasi kepada siswa, orang tua, wali, maupun masyarakat luas. Oleh karena itu pihak sekolah masih menggunakan cara manual dalam menyampaikan informasi. Sistem pemberian informasi yang berjalan saat ini masih dirasa kurang efektif dikarenakan masih berjalan secara manual dari mulut kemulut sehingga yang demikian dirasakan masih dirasakan memiliki kekurangan, antara lain jangkauan penyebarannya masih kurang luas dan muatan informasi yang terbatas.
\end{abstract}

Keyword:Sistem, Informasi, Promosi, Akademik, PHP, MySQL

ABSTRACT:The school website is a vehicle for schools to show themselves to the global community, as well as a medium of information for anyone who wants to know more about the school. The school website gets attention, good responses from various parties from education staff, students and the community. State Vocational High School 1 Lintau Buo (SMKN 1 Litau Buo) is one of the National Vocational High School Vocational Schools (SMK SSN) in Tanah Datar District which needs to interact and socialize with the wider community by providing complete and clear information about the school. Previously this school has never had an Academic Information System as a media campaign, and provision of information to students, parents, guardians and the wider community. Therefore, the school still uses manual way in conveying information. Manual way in delivering such information is felt to still have many shortcomings, such as the coverage of pemebaranya still less extensive and limited information content...

Keyword: System, Information, Promotion, Academic, PHP, MySQL

\section{PENDAHULUAN}

Penerapan sebuah situs akademik di sebuah sekolah menjadi salah satu bentuk sikap dalam mempertunjukkan atau memperlihatkan informasi kepada masyrakat. Dengan adanya situs akademik yang efektif pada sebuah sekolah dapat memberikan nilai tambah lebih baik untuk sekolah tersebut maupun untuk siswa dan walisiswa serta juga masyarakat yang ingin mengetahui informasi apasaja dari sekolah itu.

Pada Menengah Kejuruan Negeri 1 Lintau Buo (SMK N 1 Litau Buo) adalah salah satu Sekolah Menengah Kejuruan Berstandart Nasional (SMK SSN) di Kabupaten Tanah Datar yang perlu berinteraksi dan bersosialisasi kepada masyarakat luas dengan memberikan informasi yang lengkap dan jelas mengenai sekolah tersebut. Sebelumnya 
sekolah ini belum pernah mempunyai Sistem Informasi Akademiksebagai media promosi, dan pemberian informasi kepada siswa, orangtua wali, maupun masyarakat luas. Oleh karena itu pihak sekolah masih menggunakan cara manual dalam menyampaikan informasi, sehingga masih dirasakan kurang efektif, seperti jangkauan penyebaranya masih kurang luas dan muatan informasi yang terbatas.

Dari statement tersebut diatas sehingga penulis mencoba untuk melakukan sebuahpenelitian dengan judul yaitu "Perancangan Sistem Informasi AkademikPada Sekolah Menengah Kejuruan Negeri (SMKN) 1 Lintau Buo Menggunakan PHP MySQL".

Dari beberapa persoalan yang telah di paparkan pada latar belakang masalah di atas, penulis dapat mengidentifikasi masalah sebagai berikut :

1. SMK Negeri 1 Lintau Buo belum memiliki Sistem Informasi Akademik. Maka dari itu diperlukan Sistem Informasi Akademikdalam efektifitas pendukung serta syarat Sekolah Standart Nasional (SSN) dan sebagai media penyampaian informasi sekaligus promosi.

2. Pelaksanaan pendaftaran siswa baru masih dilakukan secara manual.

3. Proses efektifitas pekejaan akademik masih memakan waktu

Karena pembahasan masalah pembuatan website profil cukup luas, maka penulis membatasi beberapa masalah yaitu

objek penelitian di Sekolah Menengah Kejuruan Negeri (SMK N 1 Lintau Buo), pembuatan Sistem Informasi Akademikmenggunakan bahasa pemrograman PHP dan MySQL dan penulis membatasi masalah yang akan dibahas hanya sistem informasi, data promosi dan pendaftaran, data sekolah, data siswa, data guru data karyawan dan informasi agenda kegiatan pada sekolah menengah kejuruan (SMKN) 1 Lintau Buo.

Berdasarkan latar belakang masalah yang dibahas sebelumnya maka dapat diambil rumusan masalah yaitu bagaimana cara mendukung SMK Negeri 1 Lintau Buo memiliki syarat untuk menjadi Sekolah Standart Nasional (SSN) sebagai media penyampaian informasi dan kegiatan akademik dan bagaimana cara membantu pelaksanaan pendaftaran siswa baru secara online.

\section{METODOLOGI PENELITIAN}

Penelitian dilakukan di SMK Negeri 1 Lintau Buo.Pemilihan tempat dilakukan secara purposif (sengaja) dengan petimbangan akan kelengkapan data dan informasi yang diperlukan untuk kegiatan penelitian ini. Penelitian dilakukan pada bulan Juni 2018

Data-data yang dibutuhkan dalam penelitian ini ada 2, yaitu:

1. Data Primer

Data Primer adalah data yang didapat langsung di lapangan yaitu pada SMK Negeri 1 Lintau Buo.

2. Data sekumder

Data sekunder adalah data yang diperoleh dari buku-buku literatur, jurnal - jurnal studi kepustakaan dari SMK Negeri 1 Lintau Buo.

Sumber data yang penelitian dapatkan berasal dari pengamatan langsung pada SMK Negeri 1 Lintau Buo.

\section{HASIL PEMBAHASAN}

Adapun Hasil Implementasinya antara lain :

\section{Pengujian Sistem}


Software yang digunakan adalah software Xampp Versi 2.3 dan macromedia dreamweaver 8, Adapun langkah pengujian sistem sebagai berikut:
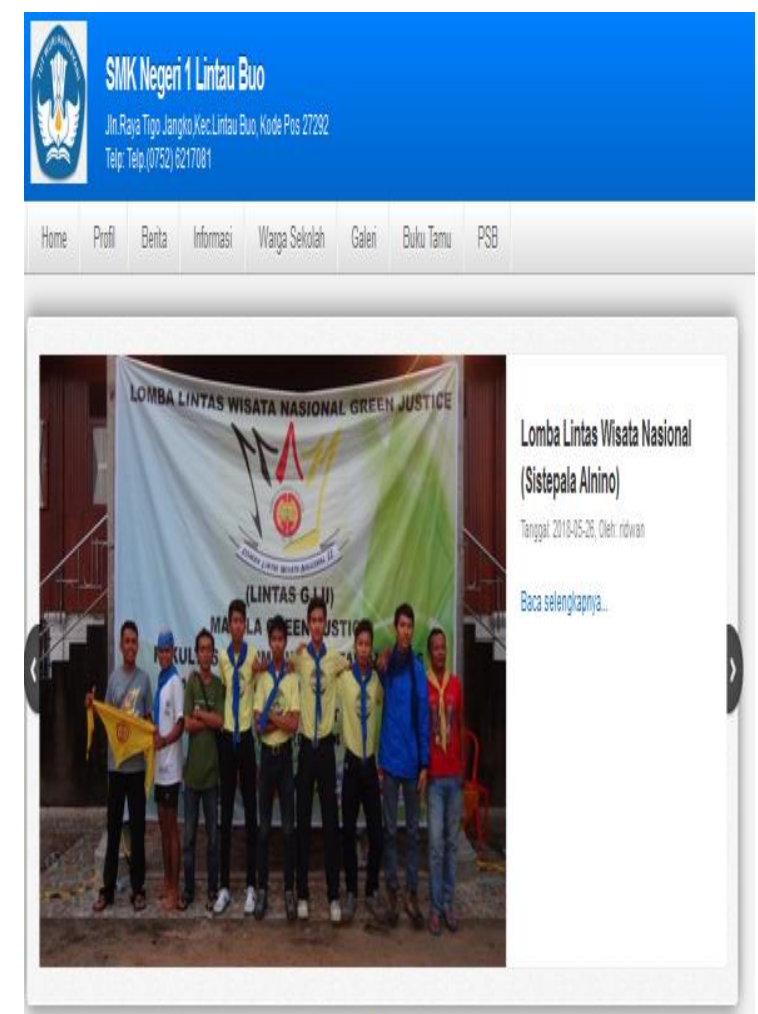

00000

Gambar 1. Home

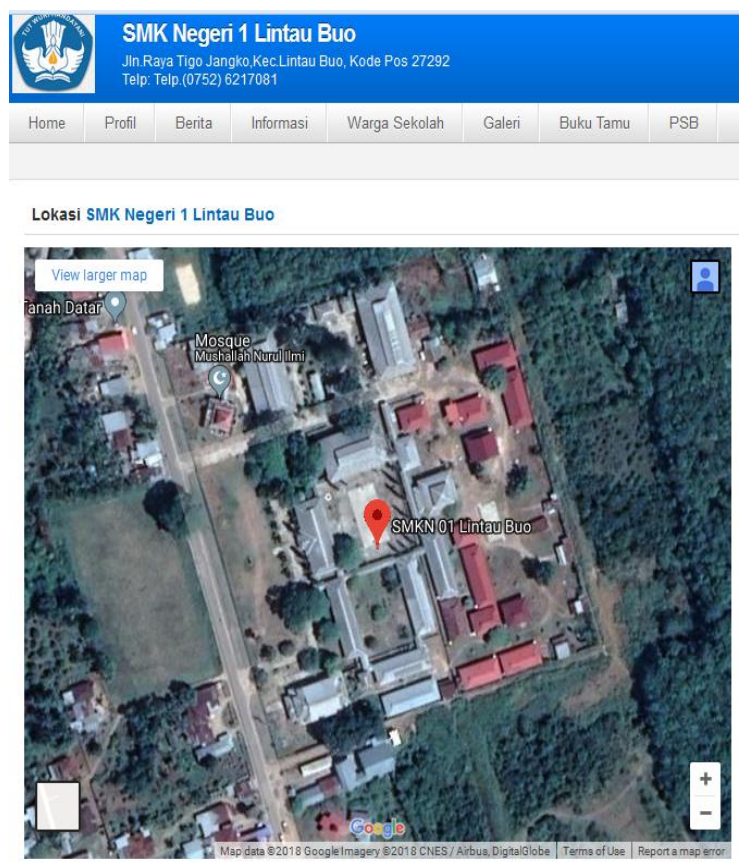

\section{Gambar 2. Lokasi Sekolah}

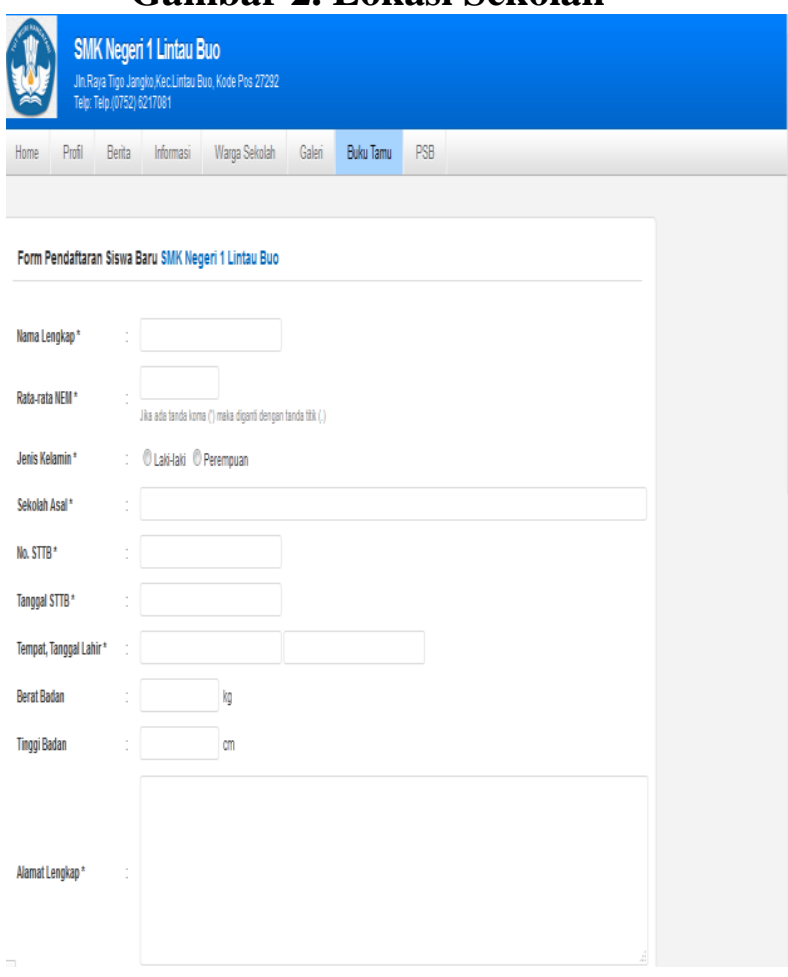

Gambar 3. Form Pendaftaran

SMK Negeri 1 Lintau Buo

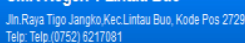

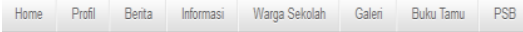

Jurusan

1. Program Studi Keahlian Banguna

a. Kompetensi Keahlian Teknik Gambar Banguna

Profil Tamatan:

- Sebagai daferer J jur gambar dalam perencanaan bangynan gedung

- Sebagal datater IJun gambar dalam pelalsanaan bangunan gedung

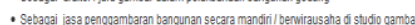

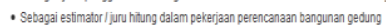

b. Kompetenns Keahlian Teknik Konstruksi Batu dan Beton

Profil Tamatan:

- Setagga perencanazan strulutur bangunan gedung,jalan danj jembatala

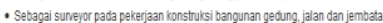

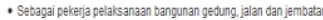

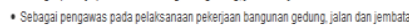

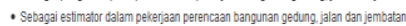

- Selagaa pembuat administrasimanamenen prover

Gambar 4. Menu Jurusan 


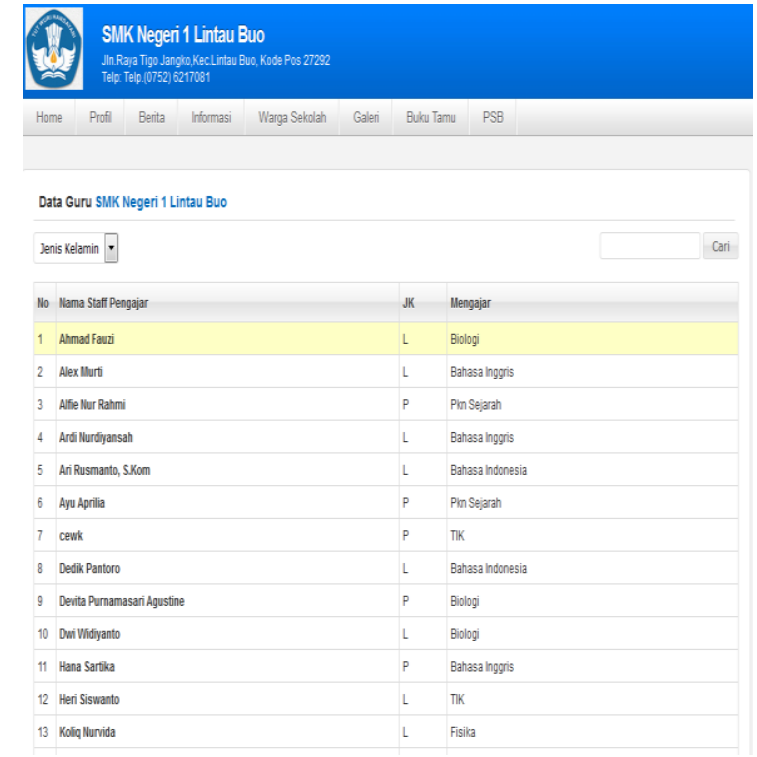

Gambar 5. Menu Data Guru

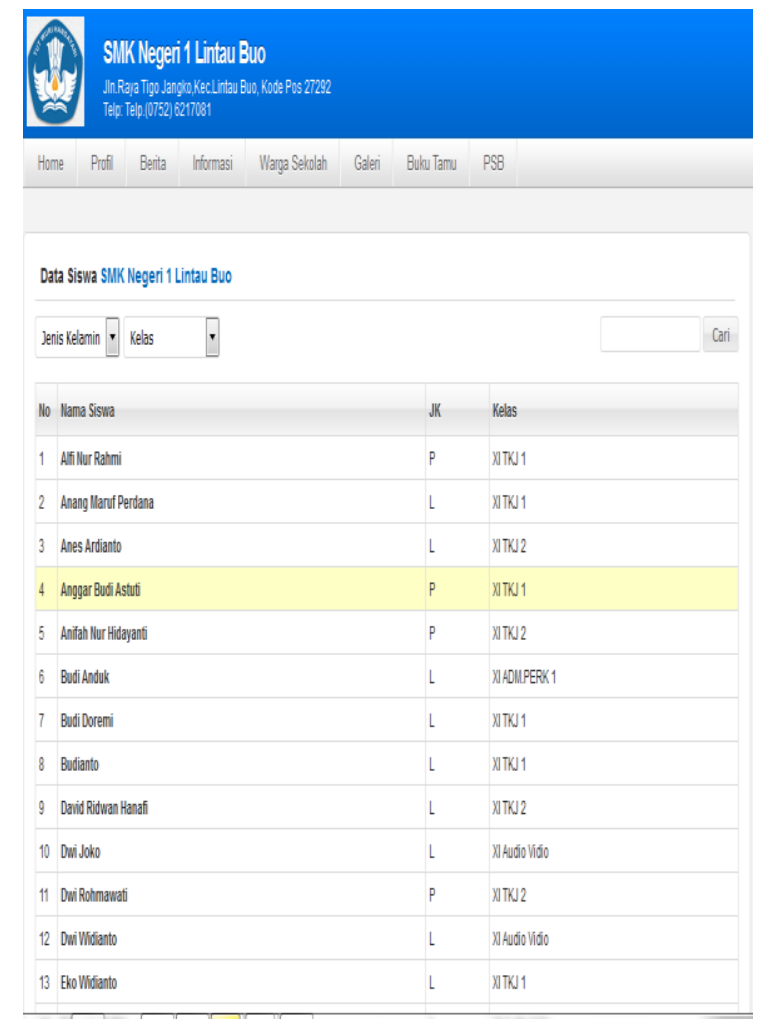

Gambar 6. Menu Data Siswa

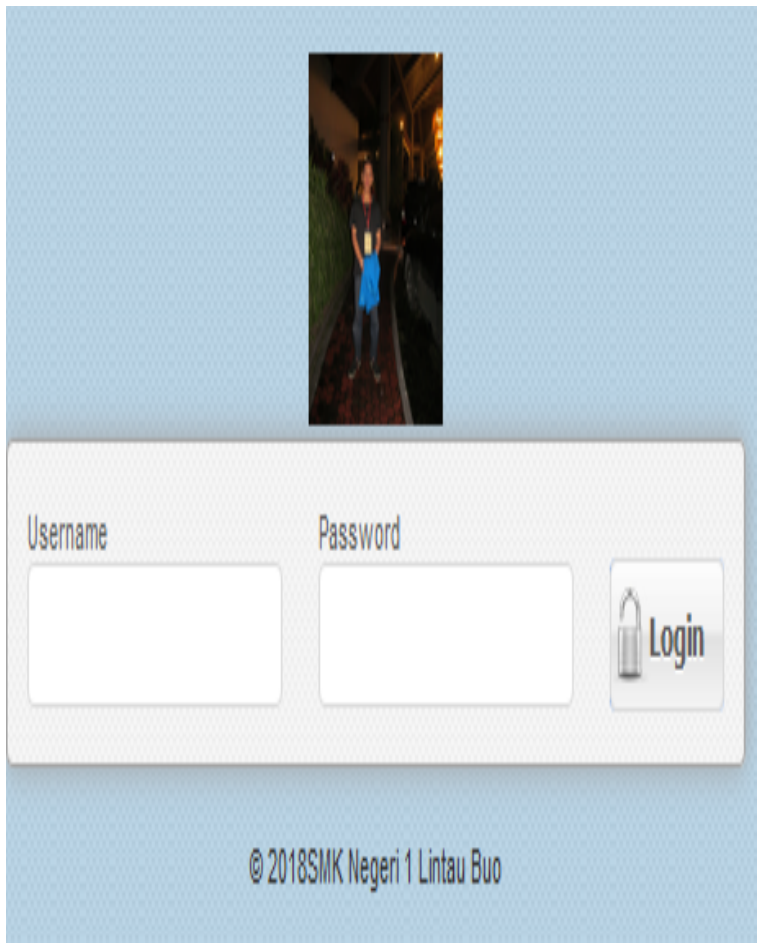

Gambar 7. Menu Login Admin

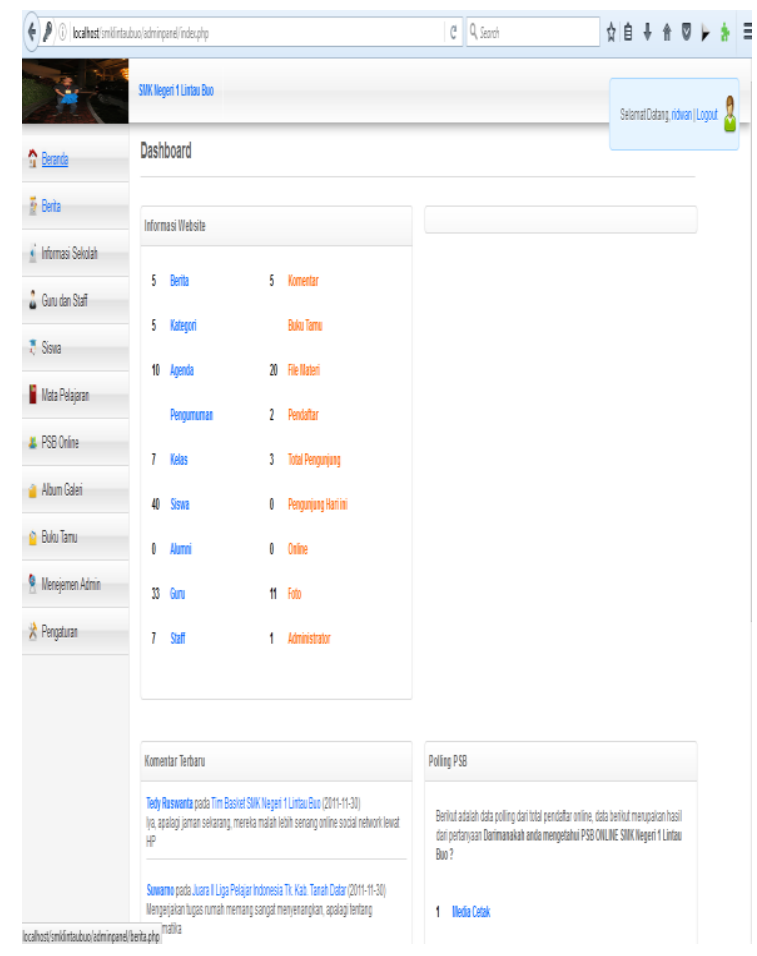

Gambar 8. Tampilan MenuAdmin 


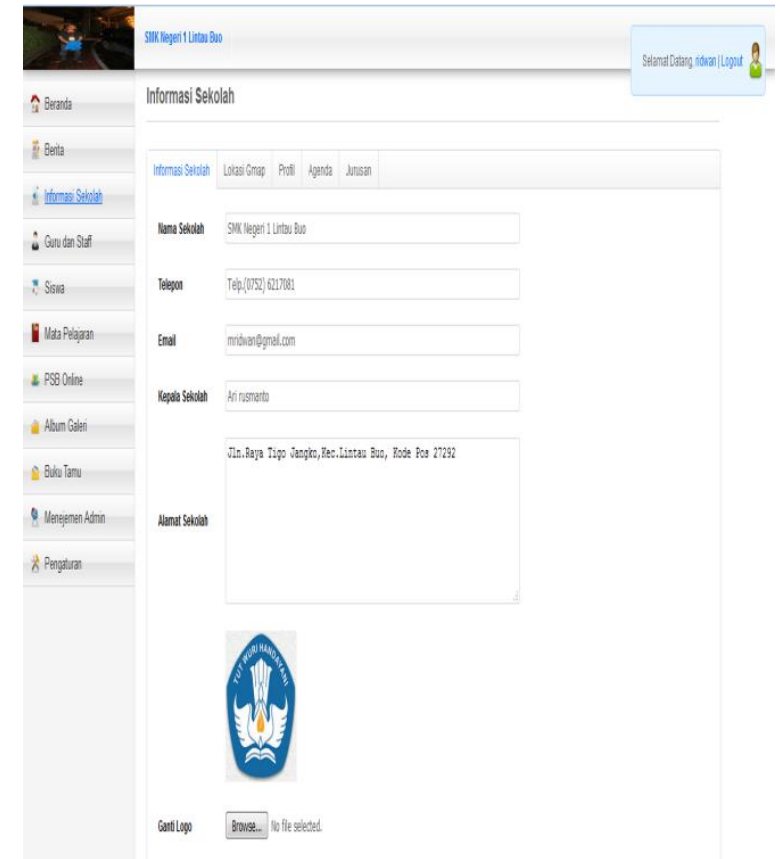

Gambar 9. Menu Edit Data Informasi Sekolah

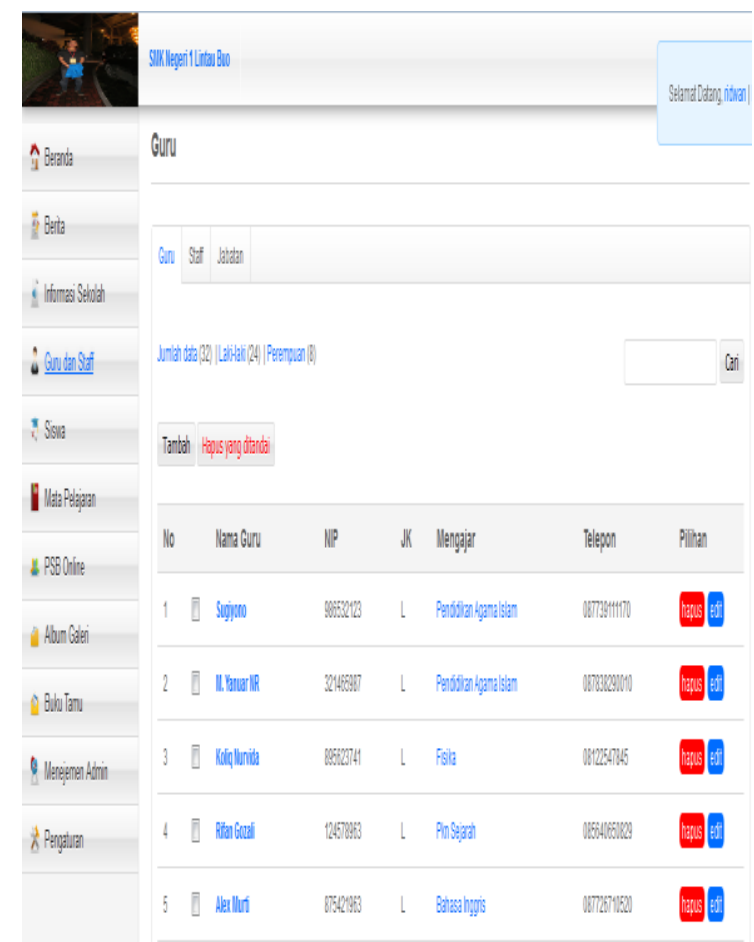

Gambar 10. Menu Edit Guru

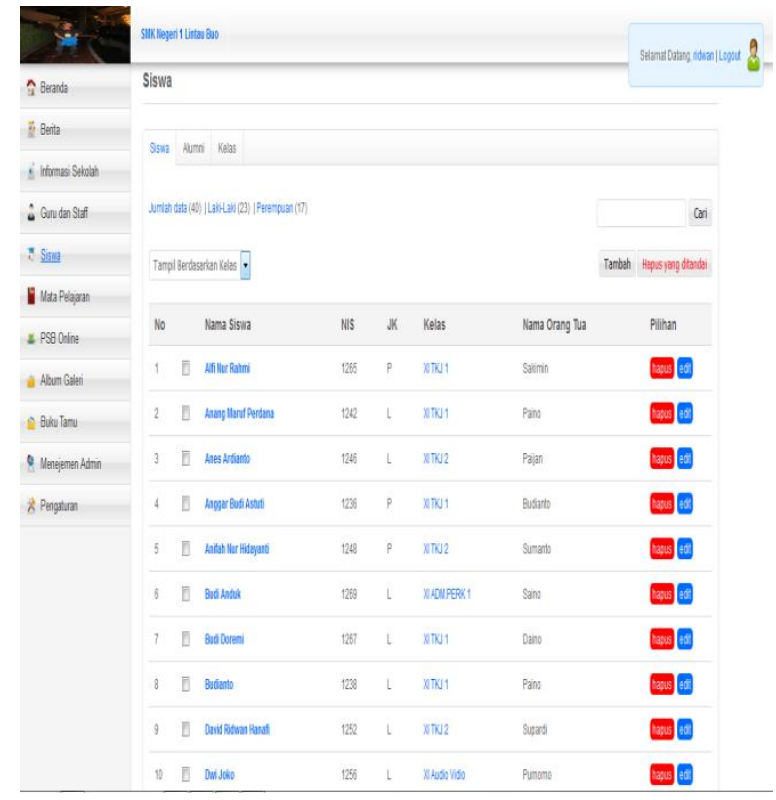

Gambar 11. Menu Edit Tampilan Data Siswa

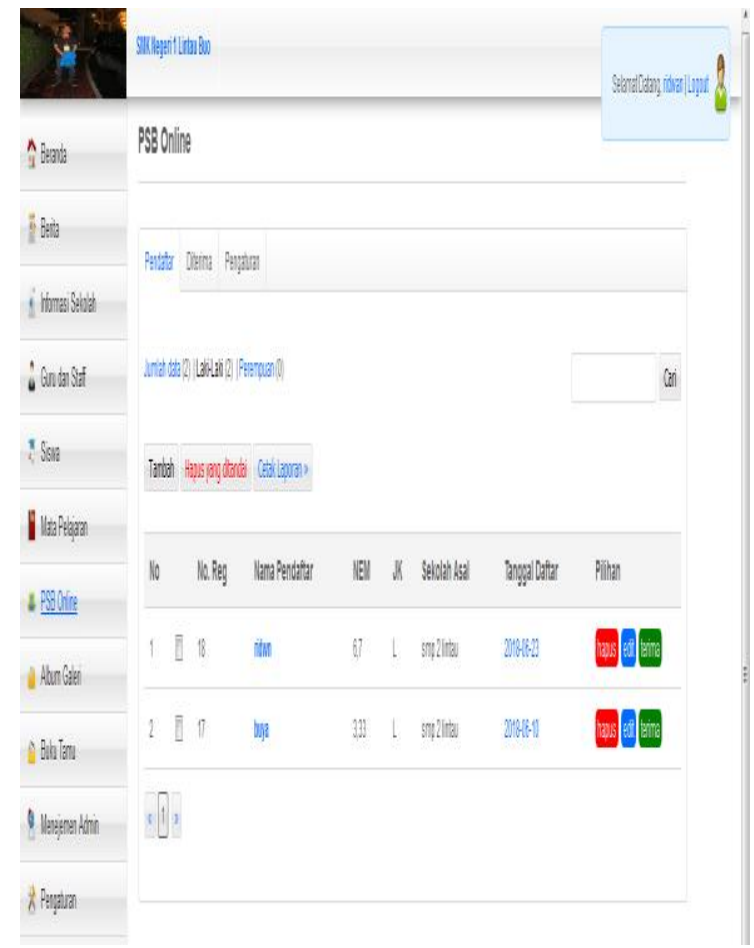

Gambar 12. Menu Tampilan PSB

\section{KESIMPULAN}

Dari penelitian yang penulis lakukan, dapat ditarik beberapa kesimpulan yaitu, dapat mengetahui program apa yang digunakan, rancangan desain situs yang sesuai spesifikasi dan 
kebutuhan dalam perancangan sistem informasi akademik SMK Negeri 1 Lintau Buo, penyampaian Informasi untuk promosi sekolah akan lebih mudah dan cepat dan efektif, dengan adanya sistem informasi akademik sekolah yang bisa diakses melalui internet, maka sekarang masyarakat umum dapat memberikan saran serta kritik, tidak perlu datang langsung ke sekolah SMK N 1 Lintau Buo.

\section{DAFTAR PUSTAKA}

Pratama, Antonius N. W. 2010. CodeIgniter : Cara Mudah Membangun Aplkasi PHP. Jakarta : MediaKita.

Simarmata, Jenner. Perancangan Basis Data. Yogyakarta: Andi.2007

Sugiarti, Yuni, S.T.M.Kom. Analisa dan Perancangan UML Generated VB6. Yogyakarta. 2013.

Sutabri, Tata. Analisis Sistem Informasi. Yogyakarta: Andi. 2012.

Sutarman. Pengantar teknologi Informasi. Jakarta. Bumi Aksara. 2009. 